\title{
The rapid evolution of UC cannabis research
}

\author{
At campuses across the UC system, cannabis researchers are grappling with questions that have \\ accompanied legalization.
}

Multiple UC campuses are establishing centers in which researchers will study the effects of legalized cannabis cultivation on water, wildlife, forests and public health.

$$
\begin{aligned}
& \mathrm{n} \\
& \mathrm{se} \\
& \mathrm{ca}
\end{aligned}
$$
n 2016, when voters approved Proposition 64, they set the stage for radical change across California's cannabis landscape. Licensed, regulated cannabis stores would soon throw open their doors. A flood of novel cannabis-derived products would make their way to market. The state's vast cannabis industry would begin to emerge from illegality, though unlicensed operations would surely persist.

UC researchers immediately understood that cannabis legalization would present California with pressing new questions, along numerous dimensions, that could only be answered through rigorous, broadranging research. How would legalized cannabis cultivation affect the state's water, wildlife and forests? How might impaired driving, or interconnections between cannabis and tobacco, influence public health? How would tax and regulatory policy affect the rate at which cannabis cultivators abandoned the illegal market? These questions and many more are now the subject of research around the UC system, and multiple campuses are establishing centers dedicated to cannabis research. This article surveys UC's emerging architecture for cannabis research in the legalization era - and presents a sampling of notable research projects, both completed and ongoing.

Online: https://doi.org/10.3733/ca.2019a0024

\section{UC Berkeley}

he Cannabis Research Center (CRC) at UC Berkeley is an interdisciplinary program that, bringing together social, physical and natural scientists, evaluates the environmental impacts of cannabis cultivation; investigates the policy-related and regulatory dimensions of cultivation; and directly engages cannabis farmers and cannabis-growing communities. The center, according to Ted Grantham - one of three CRC co-directors and a UC Cooperative Extension (UCCE) assistant specialist affiliated with UC Berkeley's Department of Environmental Science, Policy, and Management - is "focused on cannabis as an agricultural crop, grown in particular places by particular communities with unique characteristics." For Grantham and the center's co-founders, establishing the program was "a chance to develop policy-relevant research at the time of legalization and a time of rapidly shifting cultivation practices."

The center's co-directors, in addition to Grantham, are Van Butsic - a UCCE assistant specialist affiliated with UC Berkeley's Department of Environmental Science, Policy, and Management - and Eric Biber, a UC Berkeley professor of law. Other CRC researchers are associated with entities such as the

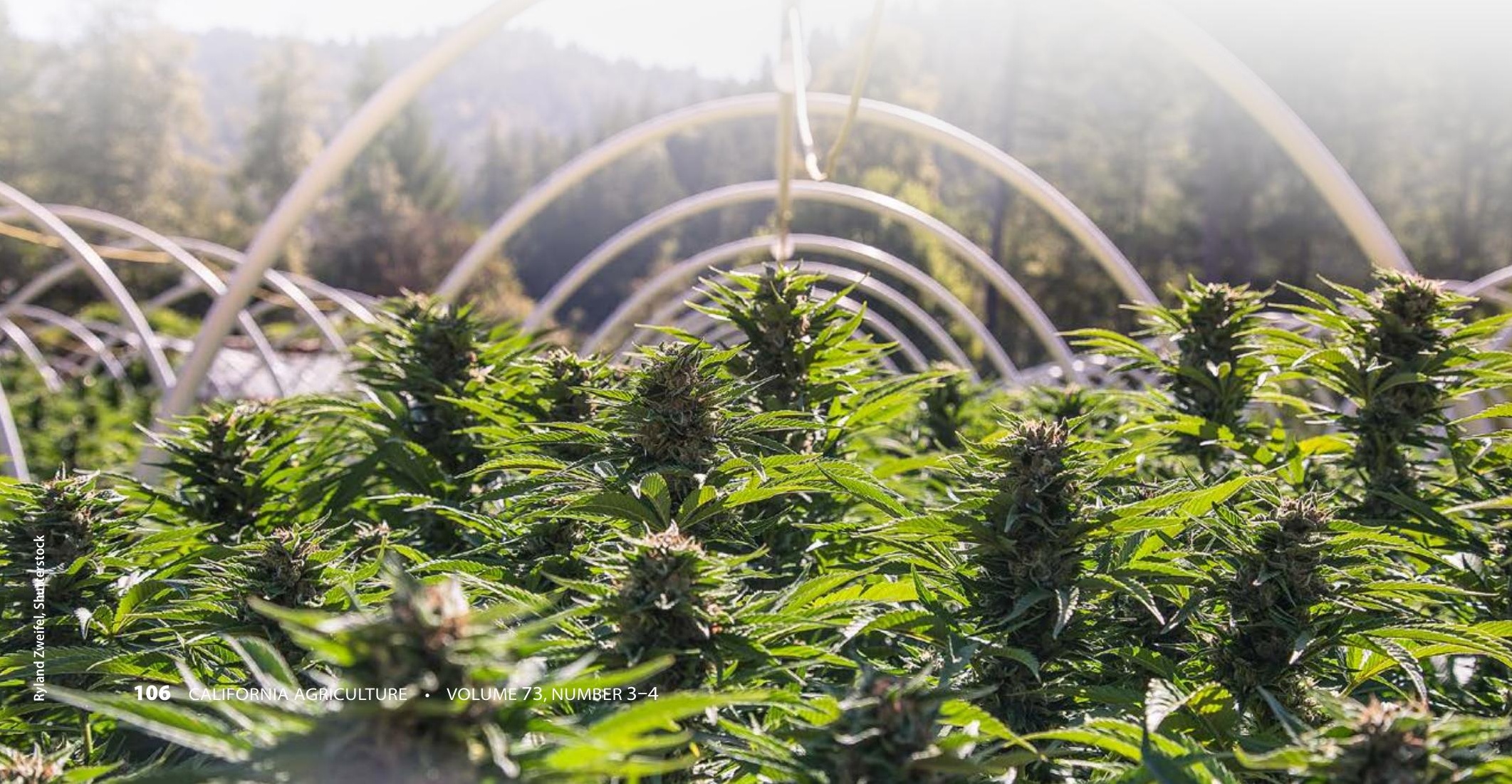


UC Berkeley Department of Integrative Biology, the UC Berkeley Geography Department, the UC Merced Environmental Engineering program and The Nature Conservancy. The center itself is affiliated with the UC Berkeley Social Science Matrix. The CRC formally launched with a public event in January.

The center's ongoing research includes a multifaceted project to assess specific aspects of Northern California's cannabis farms, including the number and size of noncompliant cultivation sites; the environmental effects of noncompliant sites (on stream habitats, for example); and the challenges to regulatory compliance that cannabis cultivators encounter. According to a grant proposal associated with the research, the project is motivated by an urgent need to understand the environmental threats posed by noncompliant farms and the reasons that some farms successfully navigate state regulations while others fail.

The researchers are combining high-resolution satellite images with local and state permitting data to identify permitted and nonpermitted cultivation sites. In parallel, the researchers are combining permit specifications with water use models to estimate the effects on stream flows of nonpermitted versus permitted cultivation. Additionally, they are determining which factors associated with cannabis cultivation are most closely linked to compliance - whether parcels are large or small, old or new - and, through written grower surveys and in-person interviews, they are seeking to understand what stands in the way of cultivator compliance. Ultimately, the work will yield a policy report outlining ways in which state and local governments can decrease the harm of noncompliant cannabis cultivation while increasing rates of compliance. The research is supported by a grant from the Campbell Foundation, provided through the Resource Legacy Fund.

In another example of CRC research focused on cannabis and the environment, last year Butsic, Jennifer Carah (a CRC-affiliated senior scientist at The Nature Conservancy) and additional co-authors published the results of their work on "agricultural frontiers" (Butsic et al. 2018). These are places where, due to increased profit potential for agricultural activity, land is newly cultivated - frequently resulting in environmental impacts such as forest fragmentation and threats to sensitive species. Such transformations, the authors write, occur when economic circumstances are altered by some new mechanism - such as, in the case of cannabis, a new legal status. The researchers, documenting the emergence of such a frontier, studied cannabis cultivation sites in Humboldt and Mendocino counties from 2012 to 2016 . Using satellite imagery to develop a database of cultivation sites, the researchers correlated site characteristics such as remoteness and erosion potential with the spread of agricultural frontiers.

They report that, over the study period, cannabis cultivation sites in the study area nearly doubled in number, with total acreage under cultivation likewise nearly doubling, and that a significant portion of the new cultivation occurred in areas such as sensitive watersheds. They found, for example, that nearly $90 \%$ of the areas newly developed for cannabis cultivation had been covered in natural vegetation as late as 2006 . The researchers argue that agricultural frontiers can develop "almost anywhere institutions fail to prevent" them - and note that, for 18 years after medicinal cannabis use became legal in California with the 1996 Compassionate Use Act, the state devoted no funds to regulating cannabis cultivation and production.

In this issue of California Agriculture, Grantham and four co-authors from the North Coast Regional Water Quality Control

Board present the results of their research into cannabis cultivators' patterns of water use in several Northern California counties. For the research that resulted in "Watering the Emerald Triangle: Irrigation sources used by cannabis cultivators in Northern California" (see page 146), Grantham and
One UC Berkeley project is motivated by an urgent need to understand the environmental threats posed by noncompliant farms and the reasons that some farms successfully navigate state regulations while others fail. his colleagues analyzed reports submitted to the board by cannabis cultivators. The researchers determined how many cultivators sourced their water from wells, surface water diversions, spring diversions and other sources; how water sourcing behavior changed over the course of a year; and how water use patterns varied according to whether growers operated within the state's legal cannabis market. The researchers determined that cannabis growers rely on well water to a greater degree than is generally supposed - and that their reliance on well water may increase as more growers join the legal market because of well water's less restrictive permitting requirements.

In separate research, Michael Polson - a postdoctoral researcher in UC Berkeley's Department of Environmental Science, Policy, and Management has investigated the environmental dimensions of cannabis from an anthropological perspective. In a paper published earlier this year, Polson shows how cannabis has been identified as an environmental problem that requires public intervention (Polson 2019). On the basis of participant observation and more than 70 interviews with subjects across the cannabis spectrum - from park rangers to environmentalists to "criminalized people" - Polson demonstrates how cannabis production has been defined as pollution - "dovetail[ing] with [cannabis] prohibition's history of marking people and substances as socially polluting." Polson argues, as he highlights the legacy of cannabis prohibition in environmental debates, that policymaking is at its most innovative when it includes a broad range of cultivators and when stigmas are explicitly addressed. 


\section{UC Davis}

esearch into the environmental aspects of cannabis is also underway at UC Davis, where Mourad Gabriel is a research associate member in UCD's School of Veterinary Medicine. In 2018, Gabriel and co-authors, including Robert Poppenga - a professor of molecular biosciences at the California Animal Health and Food Safety Lab at UC Davis - published the results of their research on the effects of rodenticides on owls in northwestern California forests (Gabriel et al. 2018). The researchers, working on privately owned timberland in Humboldt and Del Norte counties, investigated the prevalence of anticoagulant rodenticides in areas characterized by illegal cannabis cultivation. Anticoagulant rodenticides, used by some cannabis cultivators to control pests, are known to affect nontarget species in urban areas and recently have been shown to affect carnivores in California's remote forest areas as well.

Gabriel and his coauthors undertook to determine whether the northern spotted owl, a threatened species, is exposed to anticoagulant rodenticides in the study area - and also to determine if barred owls, a common species, can be used as a surrogate to determine exposure levels in northern spotted owls. The researchers analyzed liver

In a reclamation project conducted this May at 16 illegal cannabis cultivation sites in the Shasta-Trinity National Forest, a team of governmental and nongovernmental entities removed 6,000 pounds of trash, which included rodenticides and more than 5 miles of irrigation lines. UC researcher Mourad Gabriel estimates that removal of the irrigation lines restored more than 500,000 gallons of water - daily - into affected watersheds. samples from 84 barred owls and 10 northern spotted owls. (The barred owls were removed by other researchers for an unrelated project, with appropriate permits; the carcasses of northern spotted owls were discovered opportunistically.) Within the study area, $70 \%$ of northern spotted owls and $40 \%$ of barred owls tested positive for anticoagulant rodenticides. The researchers hypothesize that cannabis cultivation in the area is the main source point for the presence of dangerous rodenticides. They also determined that barred owls are a suitable surrogate for determining rodenticide levels in the threatened northern spotted owl.

Gabriel, in his capacities as a UC researcher and as executive director of the Integral Ecology Research Center, a nonprofit organization based in Humboldt County, is currently carrying out reclamation projects at illegal cannabis cultivation sites in California and Oregon. In a project conducted this May in the Shasta-Trinity National Forest, a team representing 11 governmental and nongovernmental entities worked at 16 cultivation sites within eight large cultivation complexes, removing 6,000 pounds of trash, which included rodenticides and more than 5 miles of irrigation lines. Mourad estimates that removal of the irrigation lines restored more than 500,000 gallons of water - daily - into affected watersheds. Agencies including the California Department of Fish and Wildlife and the Law Enforcement and Investigations arm of the U.S. Forest Service have provided grant funding for 170 such projects, 112 of which have already been completed.

In an entirely different vein, UC Davis-based cannabis research has been conducted since 2016 at the UC Agricultural Issues Center (AIC), a UC Agriculture and Natural Resources statewide program operating since 1985. The center's broad mission is to provide researchbased information on the economic dimensions of emerging issues in agriculture. Cannabis, then, is right in the center's wheelhouse.

Dan Sumner, the center's director, reports that AIC began pursuing cannabis-related work after the 2015 passage of a set of laws known collectively as the Medical Marijuana Regulation and Safety Act. This legislation laid the groundwork for state regulation of medicinal cannabis and ultimately of the recreational cannabis industry. The lead agency in regulating commercial cannabis licenses for distributors and retailers, among other business types, is the Bureau of Cannabis Control (BCC) - for which, between 2016 and 2018, the AIC prepared a Standardized Regulatory Impact Analysis (UC Agricultural Issues Center 2018). In the process, the AIC advised the BCC on the economic dimensions of various regulatory scenarios - and the bureau used the center's analysis to inform the final cannabis regulations that it issued on Jan. 16 of this year.

According to Sumner, a principal insight that the AIC furnished to the BCC was that, since illegal cannabis continues to be attractive to retail buyers because it is cheaper than cannabis from regulated (and taxed) retailers, "much of the cannabis sold in California [after legalization] would remain in the illegal segment." Moreover, regulations that generate benefits for consumers at lower costs will help sustain the legal marketplace.

In this issue of California Agriculture, three AIC researchers - Pablo Valdes-Donoso, a postdoctoral scholar; Robin S. Goldstein, principal economic counselor; and Sumner - present their research on California's rather stringent system for testing cannabis that enters the legal market (see page 154). All cannabis sold legally in the state is tested for more than 100 contaminants. Of those contaminants, 66 are pesticides - and tolerance for 21 of those pesticides is set at zero. 
In many cases, allowable levels of cannabis contaminants are lower than those established for food sold in the state.

The researchers, drawing on data provided by testing laboratories and manufacturers of testing equipment, estimated how much it costs to test a pound of cannabis under California's regulatory regime, as well as the cost of collecting samples. They concluded that the need to destroy batches of cannabis that fail testing accounts for a large share of testing costs. The researchers argue that, though the availability of certifiably safe and legal cannabis products may prompt some customers to join the regulated market, other customers will remain in the cheaper illegal market. They speculate that, over time, increased availability of data about cannabis testing and sales will allow for greater certainty about the effect of the testing regime on cannabis prices and demand for legal cannabis.

Meanwhile, UC Davis is establishing a dedicated center for research into psychoactive cannabis and industrial hemp - the Cannabis Research Initiative. According to Cindy Kiel, executive associate vice chancellor for research administration at UC Davis, the initiative will draw on the comprehensive strengths of UC Davis faculty in areas ranging from agricultural and environmental impacts to legal, economic and policy outcomes to human and animal health. In particular, the initiative will benefit from UC Davis's strong emphasis on agricultural issues such as soils, water, genomics and plant science and from faculty interest in two-way interactions such as those between cannabis and the environment. Funding is envisioned to flow from the UC Davis budget, from research funds established in Proposition 64 and from outside sources such as industry partners. Funding could also flow from the federal government via the National Institutes of Health. The initiative will be headed by co-directors (not yet chosen) representing the agricultural and medical sides of cannabis research.

In May, UC Davis faculty members including Chemistry Professor Mark Mascal, along with colleagues from the University of Reading in the United Kingdom, published an article (Mascal et al. 2019) demonstrating that a synthetic analogue of cannabidiol (CBD, a nonpsychoactive component of cannabis) is as effective as $\mathrm{CBD}$ in controlling seizures in rats - and that it provides several benefits in comparison to CBD. The synthetic analogue is cheaper than herbal CBD, cannot be converted into psychoactive tetrahydrocannabinol (THC) and is not restricted by the Drug Enforcement Administration's “scheduling” apparatus. Meanwhile, the UC Davis-affiliated Western Center for Agricultural Health and Safety is studying issues such as workplace safety for cannabis workers, who face risks that include unhealthy pesticide exposure. For students, UC Davis has offered cannabis courses including the graduate-level Cannabis sativa: The Plant and Its Impact on People - and, for undergraduates, Physiology of Cannabis.

\section{UC Merced}

brand-new entrant into UC cannabis research is the UC Nicotine and Cannabis Policy Center at UC Merced (NCPC), established just last year to study tobacco- and cannabis-related issues in public health and public policy, especially in the San Joaquin Valley. The center, partnering with local public health departments and organizations such as the American Heart Association, aims to produce tobacco and cannabis research that places special emphasis on the San Joaquin Valley's diverse population of teens and young adults and informs policy decisions that affect the region.

The center's flagship research initiative is a longterm, survey-based effort to understand issues surrounding cannabis, tobacco and e-cigarettes. The project is led by Bonnie Halpern-Felsher, a professor of pediatrics at Stanford University (and formerly a faculty member at UC San Francisco) and Mariaelena Gonzalez, assistant professor in public health at UC Merced. According to NCPC Director and UC Merced Associate Professor Anna Song, the researchers intend to provide data to counties that will allow them to make informed decisions about policy. Song notes that the counties in the study area are very different from, say, the Bay Area or Southern California, so state-level data isn't adequate for formulation of local tobacco and cannabis policy.
Song reports that the center's work will fill gaps in knowledge about cannabis intake behavior; epidemiological data is spotty, she says, because many people won't admit to engaging in behavior that has historically been illegal and continues to be federally illegal. The researchers are also keen to understand the interconnections between tobacco and cannabis - emerging data indicates that perceptions of tobacco risk are related to perceptions of cannabis, and the relationship between the two may affect individuals' future tobacco use. "These are the things we are trying to disentangle," Song says. (The center is conducting a parallel research project that focuses on American Indians in the same study area.)

The center was founded with a \$3.8 million grant from the TobaccoRelated Disease Research Program, a state initiative administered by the UC Office of the President, which dispenses funds derived from the Tobacco Tax Increase Initiative, a proposition approved by California voters in 2016.
The UC Nicotine and Cannabis Policy Center at UC Merced, partnering with local public health departments and organizations such as the American Heart Association, aims to produce tobacco and cannabis research that places special emphasis on the San Joaquin Valley's diverse population of teens and young adults and informs policy decisions that affect the region.

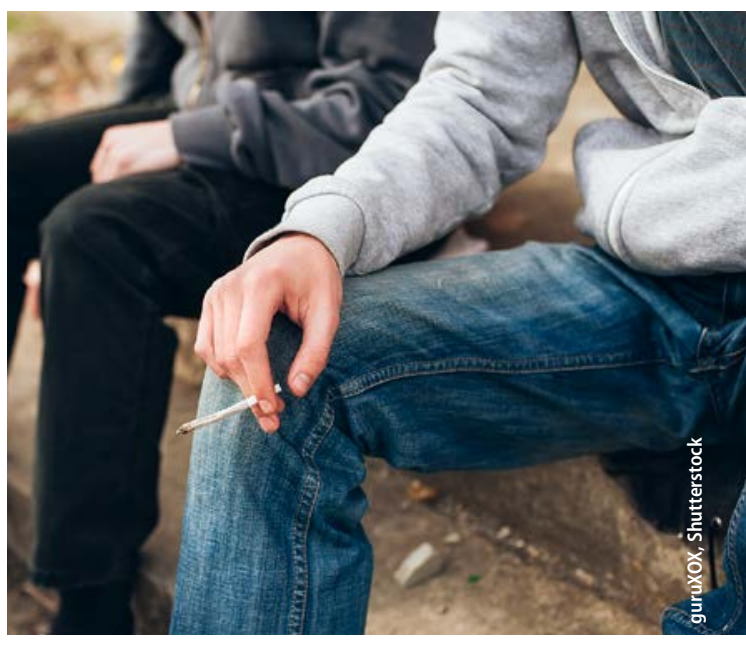




\section{UC San Diego}

annabis institutes at three UC campuses in Southern California - UC San Diego, UC Irvine and UC Los Angeles - conduct research on the health effects and medical uses of cannabis and its derivatives. But they differ greatly in their approach. The program at UC San Diego focuses closely on medical cannabis research and public safety issues. The UC Irvine program brings together medicine and law. The UCLA program has set itself the ambitious interdisciplinary task of exploring how cannabis affects society along the medical, legal, economic and social dimensions.

The UC Center for Medicinal Cannabis Research (CMCR) at UC San Diego, the oldest of the three institutes, was established when California Senate Bill 847

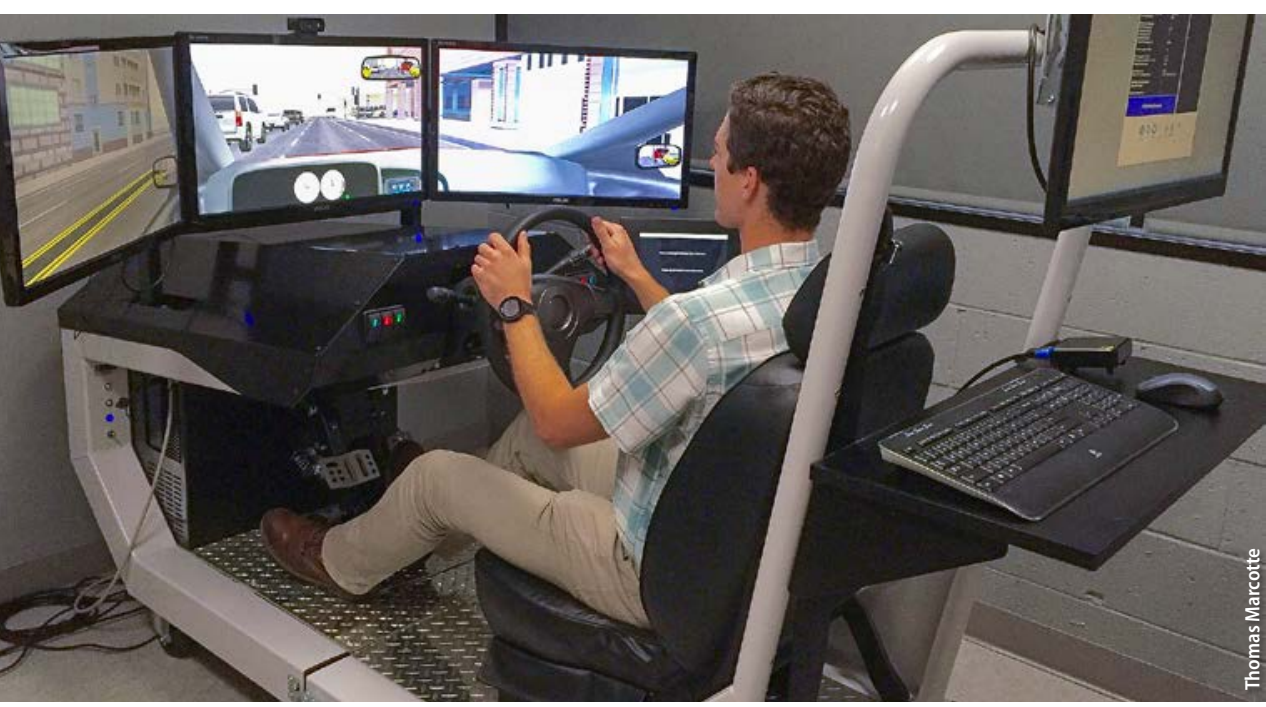

Researchers at the UC Center for Medicinal Cannabis Research at UC San Diego are studying the effect of different dosages of THC on driving. Participants complete a full day of testing in a driving simulator after consuming $\mathrm{THC}$ in specified doses. cological agent." Today, the center's cannabis research (the Marijuana Research Act of 1999) enabled UC to establish a program to "enhance understanding of the efficacy and adverse effects of marijuana as a pharmacovers a broad range of clinical conditions such as neuropathic pain, autism, bipolar disorder and early psychosis - as well as public safety issues surrounding the use of cannabis and cannabinoids.

A notable current CMCR study, authorized by the 2015 Medical Marijuana Regulation and Safety Act, seeks to better understand the effect on driving of THC. CMCR Director Igor Grant describes the study as "one of the first in the United States that looks in great detail into different dosages of THC and their effect on driving." Each research day begins with study participants - already experienced with cannabis - entering driving simulators to undergo driving assessments. Participants then consume THC in specified doses and continue over the course of the day to undergo driving assessments. Meanwhile, their bodily fluids are drawn over the course of several hours. The study seeks to determine how multiple dosing strengths of cannabis affect driving and for what duration driving impairment continues after cannabis use. The research also seeks to determine if saliva or breath tests can substitute for blood samples in determining cannabis intoxication and if sobriety tests administered with iPads can supplement standard field sobriety tests. The study is led by Thomas Marcotte, a professor of psychiatry at the UCSD School of Medicine.

Another notable CMCR study, tentatively set to begin at the end of the summer, concerns autism. The research, which includes both a clinical trial and a basic science component, investigates the effect of CBD on severe autism spectrum disorder, a condition that affects one in every 68 U.S. children. In the clinical trial - overseen by Doris Trauner, a professor of neurosciences and pediatrics at UCSD - researchers will administer oral doses of CBD or a placebo to 30 children who have been diagnosed with moderate to severe autism. CBD interacts with the endocannabinoid system, a network in the human body that regulates various physiological and cognitive processes. Researchers will attempt to determine whether CBD is safe for the study population to use, whether it addresses their symptoms, whether it alters neurotransmitters or improves brain connectivity, and if so, how.

In the basic science component of the study, researchers will use cells from the skin and blood of participants and, in Grant's words, "re-engineer these cells to be neurons - to create little brain organoids, if you will." This feat of re-engineering will allow researchers to observe how the cells function and, if CBD has benefited the subjects of the clinical trial, to investigate the associated mechanism of action. The study will be conducted with funding from the Wholistic Research and Education Foundation.

Grant notes that Proposition 64 allocates \$2 million annually to the CMCR. The center intends to use the funding partly to support its core facility and partly to fund small-scale pilot studies that might be conducted at the center itself, at other UC campuses or at campuses of other universities in California.

\section{UC Irvine}

$\triangle$ much newer entrant into medical cannabis research is UC Irvine's Center for the Study of Cannabis (CSC). As an interdisciplinary venture involving UC Irvine's School of Medicine and School of Law, the center includes basic medical science, clinical science and jurisprudence in its purview. Daniele Piomelli, director of the center - as well as a professor of anatomy and neurobiology at the UC Irvine School of Medicine - calls cannabis "a quintessential multidisciplinary problem.” Because much existing cannabis law was 
written when medical knowledge about cannabis was scarce, he says, new knowledge to underpin new legislation is urgently needed.

Piomelli further argues that because cannabis encompasses, for example, commercial and agricultural dimensions, researchers across disciplines must engage with each other (and with policymakers) to find realistic solutions to cannabis-related problems. "If medicine and science and law don't talk to one another," he says, "we'll never have sensible legislation." In that spirit, the center has two directors - Piomelli representing the medical side of the interdisciplinary undertaking and Robert Solomon, a clinical professor of law at UC Irvine School of Law, representing the legal side. About 30 faculty members across law and medicine are involved in the center's work.

The centerpiece of the CSC's work so far is an ongoing preclinical study called Impact of Cannabinoids Across the Lifespan. Piomelli, who directs the study while a team of UC Irvine principal investigators conducts the bulk of the research, characterizes it as a broad research project with many components, from which a stream of independent discoveries and publications is expected over the next 3 or 4 years. Piomelli reports that the study's main purpose is to study THC's effect on adolescents - and particularly on the adolescent brain. The human brain routinely produces neurotransmitters known as endocannabinoids - molecules, similar to cannabis derivatives, that are important in learning, memory and experiencing emotion. The key questions that the study addresses are these: Does exposure to THC, in a persistent way, change the brain's endocannabinoid system? If so, what changes at the cellular and molecular level explain the alterations? Does exposure to THC during adolescence carry lasting implications for learning and emotion? The study has received a \$9 million Center of Excellence Grant from the National Institute on Drug Abuse.

\section{UC Los Angeles}

nother new entrant into cannabis research is the Aucla Cannabis Research Initiative, founded in 2017 with a broad remit - "to understand how cannabis affects bodies, brains and society." The initiative, encompassing an interdisciplinary team of 40 faculty members from 15 university departments, aims to function as an education, research and service organization that leads public discussions of cannabis, policy and health.

The initiative got its start in the months before Proposition 64 was approved by voters. According to Jeffrey Chen, the initiative's director, leadership at the Semel Institute for Neuroscience and Human Behavior (which partially funds the initiative) anticipated that legalization would soon create the world's largest market for recreational cannabis - and that California and particularly Los Angeles would "play an outsize role in establishing normative behaviors" around cannabis. Los Angeles, in Chen's view, has become the world's cannabis capital overnight. He and his colleagues hypothesize that, given the city's status as a major tourist destination and an exporter of culture, "what happens in Los Angeles is very likely to be transmitted around the world."

So far, Chen says, the initiative's research remains mainly oriented toward health-related issues. One study - soon to start, and led by Kate Wolitzky-Taylor, an assistant clinical professor in UCLA's Department of Psychiatry and Biobehavioral Sciences - seeks to develop and evaluate a behavioral treatment for young adults who exhibit cannabis use disorder and who use cannabis to cope with anxiety, depression and the like. Cannabis, according to the researchers, is the most commonly used drug among young adults, and it can be harmful when its use qualifies as a "maladaptive way" of contending with negative experiences.
Wolitzky-Taylor reports that the research project is a randomized clinical trial focusing on participants' reactions to the anxiety and depression that might lead them to use cannabis. The treatment, she says, will draw on strategies such as "mindfulness, cognitive reappraisal skills, problem solving and ... gradual exposure to distressing but objectively safe stimuli." The treatment was developed in an iterative manner - an early version has already been tested with a small group of patients and further refinements may be made after the clinical trial is complete. The research is funded by a 3 -year, $\$ 450,000$ grant (in direct costs) from the National Institute on Drug Abuse. Individuals with cannabis use disorder, if they are 18 to 25 years old, are encouraged to email the project's coordinator, Nick Pistolesi (npistolesi@mednet.ucla.edu), regarding participation in the study.

A second example of the initiative's work is decidedly nonmedical. Brett Hollenbeck, an assistant professor of marketing at the UCLA Anderson School of Management, analyzed - along with Kosuke Uetake of Yale University - a large dataset of cannabis transactions in the state of Washington to learn about firm and consumer behavior in legal cannabis markets (Hollenbeck and Uetake 2018). Their goal was to provide policymakers, including in California, information useful for optimal development of cannabis taxation and regulation - optimal in the sense of maximizing tax revenues, safeguarding public health and discouraging a black market for cannabis.

Washington created a legal framework for growing and selling cannabis in 2012. Legal sales began there in 2014. Since then, every cannabis transaction in the state has been recorded in an administrative dataset. The researchers used the data to model consumer demand for cannabis products and measure price elasticity. Their 
analysis, covering the period from November 2014 to September 2017, indicates that Washington's strict cap on cannabis retailers - some 550 are allowed in the entire state - has permitted retailers to command high prices and behave like local monopolies.

The researchers report that when prices for regulated cannabis rise in Washington, consumers often switch to cheaper cannabis alternatives available from regulated retailers, rather than seeking out black- market cannabis. Indeed, the researchers argue that Washington's $37 \%$ sales tax rate for cannabis, though it appears high, does not drive down tax revenue, and in fact the state could generate higher revenue by raising the tax rate to $40 \%$ or higher. Further, the researchers calculate that Washington could substantially increase its revenue if it acted as the state's sole cannabis retailer, as it did for alcohol sales until 2012, and could do so without causing an increase in cannabis prices.

\section{UC Riverside}

C Riverside, though it has established no dedicated cannabis program, will soon host cannabis research for the first time. Nicholas DiPatrizio - a UC Riverside assistant professor in the School of Medicine's Division of Biomedical Sciences who is newly equipped with a DEA Schedule I license - is set to begin research investigating the effects of long-term cannabis use on metabolic diseases, including type 2 diabetes. DiPatrizio's lab, using technologies such as tandem mass spectrometry, will study how cannabis use affects glucose homeostasis (the stable equilibrium of glucose) in wild-type mice - and will also investigate whether long-term cannabis use is sometimes associated with positive health outcomes such as increases in highdensity lipoproteins (often called good cholesterol).

DiPatrizio's research has received more than $\$ 700,000$ in funding from the Tobacco-Related Disease Research Program, the same entity that provides funding for the UC Nicotine and Cannabis Policy Center at UC Merced. DiPatrizio reports that, though his research will not specifically investigate cannabis-tobacco interactions, it is eligible for the program's funding because type 2 diabetes is a tobacco-related disease.

\section{UC San Francisco}

Deturning now to Northern California, a team of UuC San Francisco researchers led by Gregory Marcus - a professor of medicine at the UC San Francisco School of Medicine - recently published an article based on their research into the influence of cannabis legalization on health care utilization (Delling et al. 2019). The researchers, analyzing a medical-coding database that contained information on 16 million hospitalizations between 2010 and 2014, sought to determine if and how Colorado's 2012 cannabis legalization had changed health care utilization in the state (with data about Oklahoma and New York providing points of comparison).

The data revealed that, after legalization, motor vehicle accidents increased by $10 \%$ in Colorado, while rates of alcohol abuse and overdoses resulting in injury or death increased by $5 \%$. (Marcus explains that the database's codes for overdose indicated that a patient had suffered an injury related to use of some drug not that patients had overdosed on cannabis per se.) Diagnoses of chronic pain, however, decreased, and the overall result was that utilization of health care services remained level. In Marcus's view, his team's research demonstrates that the repercussions of public policy tend to be complex and nuanced. In particular, even if new legislation results in certain harmful health effects, it can prove beneficial to society in other ways. No one has yet attempted an analogous study in California adult-use legalization is still very new in the state, and the availability of datasets tends to lag real-world events by several years. Marcus and his team, however, would be eager to take on the job.

\section{- Lucien Crowder}

\section{References}

Butsic V, Carah JK, Baumann M, et al. 2018. The emergence of cannabis agriculture frontiers as environmental threats. Environ Res Lett 13(12):124017. doi.org/10.1088/1748-9326/aaeade

Delling FN, Vittinghoff E, Dewland TA, et al. 2019. Does cannabis legalization change healthcare utilisation? A population-based study using the healthcare cost and utilisation project in Colorado, USA BMJ Open 9(5):e027432. doi.org/10.1136/bmjopen-2018-027432

Gabriel MW, Diller LV, Dumbacher JP, et al. 2018. Exposure to rodenticides in Northern Spotted and Barred Owls on remote forest lands in northwestern California: Evidence of food web contamination. Avian Conserv Ecol 13(1):2. doi.org/10.5751/ACE-01134-130102

Hollenbeck B, Uetake K. 2018. Taxation and power in the legal marijuana industry. Working paper. www.anderson.ucla.edu/documents/ sites/faculty/review\%20publications/research/wa_taxation.pdf

Mascal M, Hafezi N, Wang D, et al. 2019. Synthetic, non-intoxicating 8,9-dihydrocannabidiol for the mitigation of seizures. Sci Rep-UK 9:7778. doi.org/10.1038/s41598-019-44056-y

Polson M. 2019. Making marijuana an environmental issue: Prohibition, pollution, and policy. Environ Plann E 2(2):229-51. doi.org/10.1177/2514848619834847

UC Agricultural Issues Center. 2018. Economic Costs and Benefits of Proposed Bureau of Cannabis Control Regulations for the Implementation of the Medicinal and Adult Use Cannabis Regulation and Safety Act (MAUCRSA): Standardized Regulatory Impact Analysis. Report prepared for the California Bureau of Cannabis Control. www. dof.ca.gov/Forecasting/Economics/Major_Regulations/Major_ Regulations_Table/documents/DCA_Cannabis_SRIA_2018.pdf 